\title{
Identification of a barrier height threshold where brook trout population genetic diversity, differentiation, and relatedness are affected
}

\author{
Anne Timm • Eric Hallerman • C. Andrew Dolloff • \\ Mark Hudy • Randall Kolka
}

Received: 30 December 2014 / Accepted: 1 December 2015 /Published online: 22 December 2015

(C) Springer Science+Business Media Dordrecht (outside the USA) 2015

\begin{abstract}
The overall goal of the study was to evaluate effects of landscape features, barriers, on Brook Trout Salvelinus fontinalis population genetics and to identify a potential barrier height threshold where genetic diversity was reduced upstream of the barrier and differentiation and relatedness increase. We screened variation at eight microsatellite DNA loci within Brook Trout populations upstream and downstream of ten putative natural barriers ranging in height from 1.5 to $61 \mathrm{~m}$ to quantify allelic variation, differentiation $\left(F_{\mathrm{ST}}\right)$, individual assignment probability $(Q)$, and relatedness $\left(r_{\mathrm{xy}}\right)$. Average gene diversity per locus $(H)$, differentiation $\left(F_{\mathrm{ST}}\right)$, and mean relatedness values $\left(r_{\mathrm{xy}}\right)$ became significantly greater in relation to barrier height starting at
\end{abstract}

A. Timm $(\bowtie)$

USDA Forest Service, Northern Research Station, 5523 Research Park Drive, Suite 350, Baltimore, MD 21228, USA

e-mail: altimm@fs.fed.us

E. Hallerman

Department of Fish and Wildlife Conservation, Virginia Tech

University, 100 Cheatham Hall, Blacksburg, VA 24061, USA

C. Andrew Dolloff

USDA Forest Service, Southern Research Station, 1710 Research Center Drive, Blacksburg, VA 24060, USA

M. Hudy

US Geological Survey, Ecosystems, 12201 Sunrise Valley Drive, Mail Stop 301, Reston, VA 20192, USA

R. Kolka

USDA Forest Service, Northern Research Station,

1831 Hwy. 169 E., Grand Rapids, MN 55744, USA
$4 \mathrm{~m}$ according to piecewise linear regression. This potential barrier height threshold is greater than the barrier height criterion identified for Brook Trout based on physical criteria and jumping ability $(0.74 \mathrm{~m})$. The $4 \mathrm{~m}$ barrier-height criteria can be used to identify barrier sites where Brook Trout populations may be at risk due to reduced genetic diversity and increased relatedness.

Keywords Barrier-Brook Trout - Genetic differentiation $\cdot$ Individual assignment $\cdot$ Relatedness

\section{Introduction}

Natural and anthropogenic barriers to fish movement within streams are significant sources of habitat fragmentation that affect distributions of fish populations across landscapes (Gibson et al. 2005; Gosset et al. 2006; Sheer and Steel 2006; Poplar-Jeffers et al. 2009). Information on the specific conditions that constitute a barrier to movement for particular fish species is limited. Depending on the species' swimming ability, jumping ability, and fish individual size, conditions that create barriers to upstream movement include excess drop, high or low velocity, and excessive channel slope. Physical complexity and flow variability may exacerbate the barriers and influence the likelihood that particular cascades or waterfalls will be barriers to fish movement (Belford and Gould 1989; Adams et al. 2000; Reiser et al. 2006). This study focuses on Brook Trout Salvelinus fontinalis, the native trout species of the eastern United States, which has a previously documented maximum jump height. For Brook Trout 8.6 
to $34.0 \mathrm{~cm}$ total length (TL), Kondratieff and Myrick (2006) documented a 0.74 m maximum jump height at baseflow over a flashboard flume artificial waterfall in the laboratory. In the field, Adams et al. (2000) documented a $21.0 \mathrm{~cm}$ TL Brook Trout ascending a $1.5 \mathrm{~m}$ falls and a $9.0 \mathrm{~cm}$ TL Brook Trout ascending a $0.70 \mathrm{~m}$ falls in highgradient streams in the western United States.

A height barrier to upstream movement such as a waterfall can impede gene flow, which may result in genetic isolation, reduced genetic diversity, and increased genetic differentiation (Shrimpton and Heath 2003; Gibson et al. 2005; Hudy et al. 2010). Previous research has applied microsatellite DNA markers to detect genetic differences between upstream and downstream trout populations adjacent to barriers of various heights as indicators of barrier effects. To quantify barrier effects, researchers have used genetic differentiation $\left(F_{\mathrm{ST}}\right)$, heterozygosity $(H)$, number of alleles per locus $(A)$, and probability of individual assignment to their correct source population $(Q)$ (Castric et al. 2001; Taylor et al. 2003; Yamamoto et al. 2004; Poissant et al. 2005; Wofford et al. 2005; Whiteley et al. 2006; Deiner et al. 2007; Small et al. 2007; Guy et al. 2008). For example, Deiner et al. (2007) sampled Rainbow Trout Oncorhynchus mykiss at barrier sites ranging in height from 3 to $21.3 \mathrm{~m}$ and found a significantly lower number of alleles upstream of barriers, and higher individual assignment probabilities upstream of barriers $(81.3 \%)$ compared to downstream of barriers $(74.4 \%)$. Other research documented lower allelic diversity upstream of barriers and higher differentiation between upstream and downstream populations at barriers ranging in height from 5 to $30 \mathrm{~m}$ for Coastal Cutthroat Trout Oncorhynchus clarkii clarkii populations (Wofford et al. 2005; Guy et al. 2008) and for Brook Trout populations at barriers $>10 \mathrm{~m}$ (Poissant et al. 2005).

In addition to using genetic diversity, differentiation, and individual assignment probability to quantify barrier effects on trout populations, quantifying relatedness among individuals could also be applied to further investigate effects of barriers on gene flow (Belkhir et al. 2002; Kalinowski et al. 2006; Jones and Wang 2009; Coombs et al. 2010; Kanno et al. 2011). High relatedness among parents and offspring associated with all Brook Trout redds upstream of a putative barrier could indicate only interbreeding among spawners upstream of the barrier and a lack of dispersal of new colonizing spawning adults from downstream (Kuligowski et al. 2005; Kalinowski et al. 2006; Hudy et al. 2010).
Although, these previous studies identified effects of barriers on salmonid population genetics associated with barriers that ranged in height from 3 to $21.3 \mathrm{~m}$ (Deiner et al. 2007) for Rainbow Trout and 5 to $30 \mathrm{~m}$ (Wofford et al. 2005) for Coastal Cutthroat Trout, they did not attempt to identify a height threshold where differences between upstream and downstream allelic diversity and individual assignment probabilities and differentiation became statistically significant. These previous studies also assumed a priori that putative barriers of certain heights were barriers to genetically effective migration without information verifying that specific heights resulted in statistically different diversity, assignment, or differentiation values.

This was the first study to sample Brook Trout populations directly upstream and downstream of putative barriers ranging in height from 1.5 to $61 \mathrm{~m}$ across two ecoregions in the eastern United States in order to quantify population genetic effects upon the respective local populations. In this study, we tested the hypotheses that Brook Trout population genetic diversity, differentiation, individual assignment probability, and relatedness upstream and downstream of barriers differed in relation to barrier height. The larger range of heights associated with this study allowed us to test the hypothesis that there is a height threshold where genetically-effective migration, or gene flow, between upstream and downstream populations of Brook Trout is significantly reduced. Finding a height threshold value where the barrier affects geneticallyeffective migration is important for maintaining genetic diversity and managing stream fish populations at the watershed scale where both anthropogenic and natural barriers occur. Identifying a height threshold where the fish population upstream of a barrier is at additional risk due to reduced gene flow could be used to identify high priority populations for management within a watershed. In addition, heights that impede jumping and swimming abilities for fish have been used as criteria to identify anthropogenic barriers as impassable (Belford and Gould 1989). Identifying a height known to affect genetically-effective migration would be an additional tool for prioritizing anthropogenic barrier removal.

In relation to the hypothesis that there is a height threshold that results in reduced gene flow, we predicted that the following effects would occur: 1) significantly less allelic diversity, measured as total number of alleles, average gene diversity per locus $(H)$, and number of alleles per locus $(A)$ upstream of the barrier when compared to downstream of the barrier; 2) significantly greater $F_{S T}$ values between upstream and downstream 
populations with greater barrier height as the upstream sample is further differentiated from the downstream sample; 3) significantly higher relatedness $\left(r_{x y}\right)$ upstream of the barrier when compared to downstream of the barrier due to isolation from a larger number of spawners downstream of the barrier; and 4) significantly greater individual assignment probabilities upstream of the barrier when compared to downstream of the barrier.

Previous research also indicated differences in genetic variation among Brook Trout populations within major drainages (Perkins et al. 1993; Danzmann et al. 1998) and among Coastal Cutthroat Trout populations within ecoregions (Guy et al. 2008). Therefore, this study tests our predictions using sites selected from two ecoregions to address these potential effects on data analysis. Stocking programs for various trout and salmon species have had mixed effects on genetic diversity of supplemented populations, ranging from no effect to negative effects (Hansen et al. 2000; Heggenes et al. 2006; Small et al. 2009) as well. Previous research has documented effects of stocked fish on trout species up to 20 years (Heggenes et al. 2006). Therefore, sites were selected that either have not been stocked or have not been stocked in the last 20 of years, to eliminate the potential influence of stocking on genetic diversity metrics. Previous research has documented similar effects of natural waterfall barriers and anthropogenic barriers on genetic diversity and population genetic structure at larger scales (Deiner et al. 2007). Therefore, we believe that analysis of data at natural barriers is relevant to anthropogenic barriers as well.

\section{Materials and methods}

A total of 10 sites with putative natural barriers and one site with no barrier were selected in subwatersheds (USGS 6th-level Hydrologic Units) of the eastern United States (Fig. 1) that were at least $68 \%$ forested, which is known to be significantly correlated to the presence of successfully-reproducing Brook Trout populations (Hudy et al. 2008). Heights for the 10 putative barriers ranged from 1.5 to $61 \mathrm{~m}$ (Table 1), with all putative barriers meeting the minimum $0.74 \mathrm{~m}$ height considered a barrier to upstream movement for 8.6 to $34.0 \mathrm{~cm}$ TL Brook Trout (Kondratieff and Myrick 2006). Sites were selected from the heavily-glaciated Northern Lakes and Forests Level III Ecoregion and the unglaciated Blue Ridge Level III Ecoregion to rule out differences in genetic diversity that could occur at the ecoregional scale and to investigate the consistency of genetic diversity patterns upstream and downstream of barriers regardless of ecoregion (Bailey 2005; Guy et al. 2008). Sites were also selected based on historic and current survey information that identified locations with sufficient Brook Trout population densities to collect at least 30 juveniles and adults upstream and downstream of each natural barrier, the sample size considered a minimum for reliably estimating genetic diversity of populations (McCracken et al. 1993; Rogers and Curry 2004).

\section{Stocking information}

Stocking, or unauthorized movement, could affect comparisons of genetic diversity, differentiation, individual assignment, and relatedness between sites and between upstream and downstream samples at a given site if a stream is stocked downstream of a barrier and not upstream of a barrier, or vice versa. This would be the result of differences between alleles and kinship relationships found in the stocked fish and the fish already found within the stream. Brook Trout has been influenced by stocking throughout its range. For example, historic information shows that stocking occurred at different times throughout the Blue Ridge Level III Ecoregion from 1941 to the present and among the Northern Lakes and Forests Level III Ecoregion from 1956 to the present. Despite stocking influence, natural genetic diversity and population structuring still occur to a large extent throughout the range of the species (Danzmann and Ihssen 1995; Danzmann et al. 1998; Hall et al. 2002; Rogers and Curry 2004; D'Amelio et al. 2008; Wilson et al. 2008).

Occurrence of stocking can only be verified reliably by stocking records compiled by state agencies in charge of stocking programs. Unintentional stocking or undocumented movement of fish from one location to another by the public is always possible in any stream in the United States, but this could not be verified and was considered negligible for the sake of our analysis. Of the ten sites, and one non-barrier site identified for this study, state agency records document no stocking at the following six sites at the sampled location or in connected waters according to fisheries biologists from the Virginia Department of Game and Inland Fisheries (VDGIF) and Michigan Department of Natural Resources (MI DNR): Apple Orchard Falls, Virginia 
(Thom Teears, VDGIF, personal communication, November 15, 2013); Cascades, Virginia (Joe Williams, VDGIF, personal communication, November 12, 2013); Cabin Creek, Virginia (George Palmer, VDGIF, personal communication, November 12, 2013); North Fork Stony Creek, Virginia (non-barrier site) (Joe Williams, VDGIF, personal communication, November 12, 2013); Shoe Creek Cascade, Virginia (Thom Teears, VDGIF, personal communication, November 15, 2013); and Cole Creek, Michigan (Darren Kramer, MI DNR, personal communication, November 20, 2013).

The following five sites were stocked both upstream and downstream of the sample location between 1941 and 1980, (according to fisheries biologists from VDGIF, North Carolina Wildlife Resources Commission (NCWRC), Wisconsin Department of Natural Resources (WI DNR), and Minnesota Department of Natural Resources (MN DNR): Saint Mary's Falls, Virginia (stocked until 1972, Thom Teears, VDGIF, personal communication, November 15, 2013); Sassafras Falls, North Carolina (1941 stocking record, Jacob Rash, NCWRC, personal communication, December 19, 2013); Morgan Falls, Wisconsin (not stocked since 1956, Lawrence Eslinger, WI DNR, personal communication, November 11, 2013); Spring Brook, Wisconsin (not stocked since 1962, Lawrence Eslinger, WI DNR, personal communication, November 11, 2013); and Portage Brook, Minnesota (not stocked since 1980, Steve Persons, MN DNR, personal communication, November 12, 2013).

\section{Study site measurements}

Barrier height was measured in the field using a standard rod and level and measuring tape up to $7.5 \mathrm{~m}$ with $\mathrm{a} \pm 0.05$ $\mathrm{cm}$ accuracy, or was estimated by subtracting the difference in elevation between GPS points recorded directly upstream of the barrier and directly downstream of the barrier, with an accuracy \pm 3 to $5 \mathrm{~m}$ if the height was greater than $7.5 \mathrm{~m}$. The difference in elevation based on Google Earth high-resolution satellite imagery of 1000 pixels was also used to verify differences in GPS points if the barrier height was taller than the standard rod $(7.5 \mathrm{~m})$. Channel gradient was estimated as arctan (degrees) based on change in height $(\mathrm{m})$ from the lowest to highest point of each barrier.

Population genetic sampling

Single-pass, dual-anode backpack electrofishing techniques were used to collect Brook Trout at each site.
Fig. 1 a Study sites sampled in the Northern Lakes and Forests Level III Ecoregion (Bailey 2005). The four natural barrier sites included Portage Brook, Minnesota (PRBR), Morgan Falls, Wisconsin (MORG), Spring Brook, Wisconsin (SPBK), and Cole Creek, Michigan (COLE) b Study sites sampled in the Blue Ridge Level III Ecoregion (Bailey 2005). The six natural barrier sites represented by the circle symbol included Sassafras Falls, North Carolina (SASS); Cabin Creek, Virginia (CBCR); Cascades, Virginia (CASC); Apple Orchard Falls, Virginia (APOR), Saint Mary's Falls, Virginia (STMY), and Shoe Creek Cascade, Virginia (SHCS). The non-barrier site, represented by the triangle symbol, was North Fork Stony Creek (NFKS)

Stream reach sample distances ranged from 50 to $200 \mathrm{~m}$, as sampling was completed at a given site once 30 Brook Trout fin clips from individuals $\geq 5 \mathrm{~cm}$ total length were acquired. Fish were sampled from all available age classes and there were no significant differences in total lengths between the upstream and downstream-barrier sample at selected sites. Fish were anesthetized with clove oil, total lengths and weights were measured, and $\sim 50 \mathrm{mg}$ pieces of fin were clipped from each trout (Taylor and Roberts 1999; Rogers and Curry 2004). Fin clips were stored and preserved in separate vials with $95 \%$ ethanol.

DNA was extracted from 657 fin clips and polymerase chain reaction (PCR) amplified with microsatellite-bearing fragments at eight loci (Table 2) using an MJ DNA Engine Dyad PTC-220 thermocycler. Microsatellite loci were multiplexed (Henegariu et al. 1997; Table 2) for costeffective genotyping using an Applied Biosystems, Inc. ABI 3100-Avant Autoanalyzer and GeneMapper software. Genotypes were scored using Peak Scanner v 1.0 (Applied Biosystems, Inc).

Population genetic analysis

In this study, we tested the hypotheses that Brook Trout population genetic diversity, differentiation, individual assignment probability, and relatedness upstream and downstream of barriers differed in relation to a barrier height threshold. To test these hypotheses, piecewise linear regression was applied using SAS 9.3 (SAS Institute, Inc. 2011) to test for significant relationships between specific ranges of barrier heights and upstream values of: total number of observed alleles, number of alleles per locus $(A)$, average gene diversity per locus $(H)$, mean relatedness $\left(r_{\mathrm{xy}}\right)$, and individual assignment probability $(Q)$. Piecewise linear regression was also applied to test for significant relationships between 

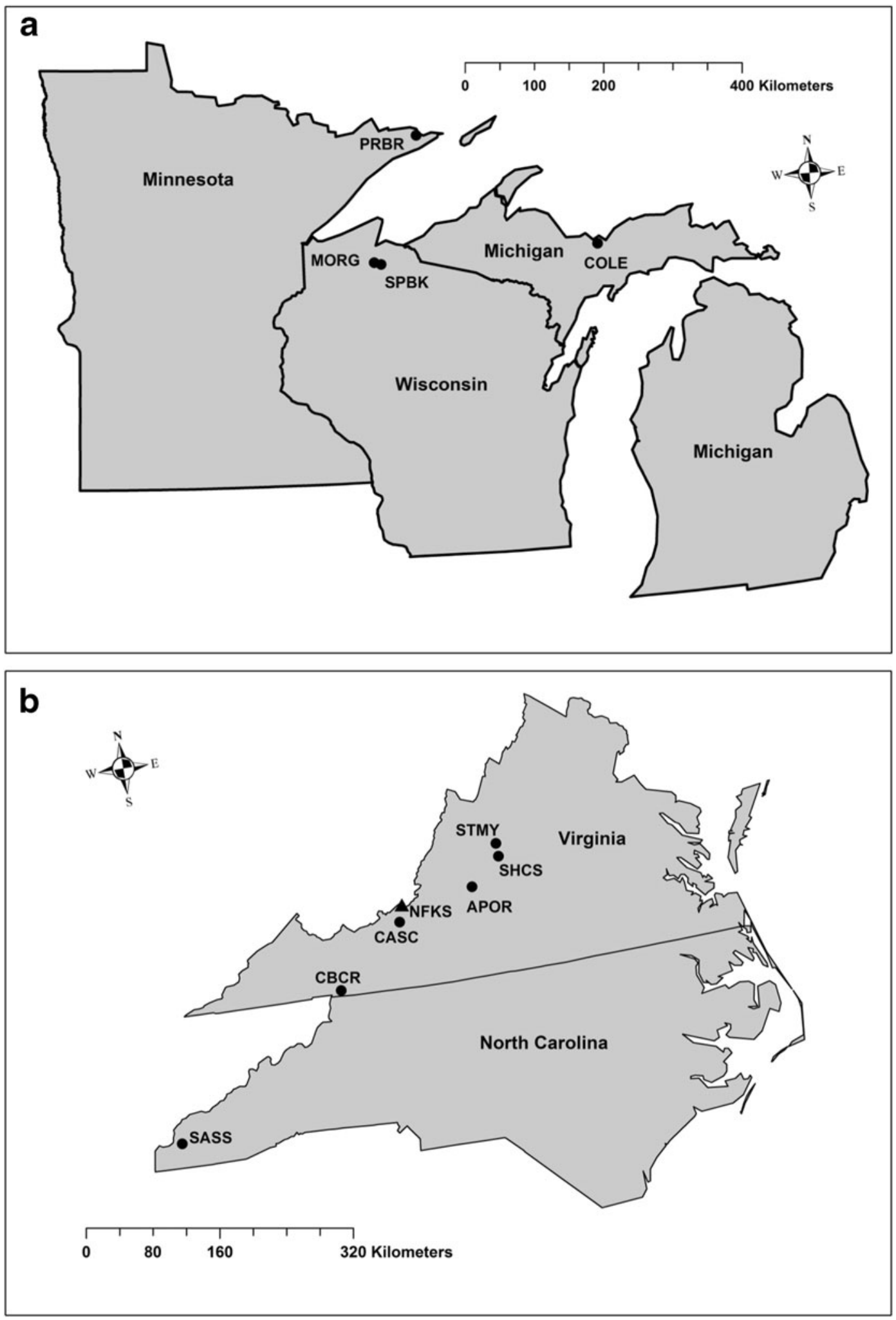
Table 1 Study sites and associated heights of putative barriers for Brook Trout populations

\begin{tabular}{ll}
\hline Site name & Barrier height (m) \\
\hline Apple Orchard Falls, Virginia & 61.0 \\
Sassafras Falls, North Carolina & 30.0 \\
Morgan Falls, Wisconsin & 23.0 \\
Cascades, Virginia & 21.3 \\
Cabin Creek, Virginia & 7.6 \\
Portage Brook, Minnesota & 6.4 \\
Cole Creek, Michigan & 4.3 \\
Saint Mary's Falls, Virginia & 4.0 \\
Shoe Creek Cascade, Virginia & 3.4 \\
Spring Brook, Wisconsin & 1.5 \\
North Fork Stony Creek, Virginia & 0.0 \\
\hline
\end{tabular}

specific ranges of height and differentiation, $F_{\mathrm{ST}}$, between upstream and downstream samples. Piecewise linear regression applied multiple linear models to the above data for different ranges of height to identify potential breakpoints where the slope of the linear function changed and the relationship to height became more significant. A breakpoint that identified the minimum barrier height that had an effect would occur when the piecewise model fit the data more significantly than the linear model, as shown by smaller mean square error (MSE), a greater $r^{2}$ value, and a lower $P$ value (Ryan et al. 2007).

To test the predictions that there would be significantly less genetic diversity upstream of barriers and greater differentiation between upstream and downstream samples in relation to a barrier height threshold, we applied Arlequin 3.1.1. (Excoffier et al. 2005) to quantify the total number of observed alleles, number of alleles per locus $(A)$, average gene diversity per locus $(H)$, and $F_{\mathrm{ST}}$ (Weir and Cockerham 1984). Genetic diversity metrics were quantified following the approach used by Neraas and Spruell (2001), Rogers and Curry (2004), and Yamamoto et al. (2004). We applied GENEPOP (Rousset 2007) to test for deviation from Hardy-Weinberg equilibrium at each locus and for linkage disequilibrium for all locus pairs within a population. Wilcoxon, nonparametric normal approximation one-sided tests for two independent samples were then applied using SAS 9.3 (SAS Institute, Inc. 2011) to test for significant differences between the number of total alleles, $H$, and $A$ upstream and downstream of barrier sites. Results from the piecewise linear regression analysis were used to test the prediction that there would be greater differentiation between upstream and downstream samples in relation to different ranges of barrier heights.

To test the prediction that there would be significantly greater relatedness $\left(r_{\mathrm{xy}}\right)$ upstream of the barrier than downstream of the barrier, we applied the IDENTIX program (Belkhir et al. 2002) to calculate a mean $r_{\mathrm{xy}}$ value for each upstream- and downstream-barrier sample by applying Queller and Goodnight's (1989) pairwise relatedness estimator. Wilcoxon, nonparametric normal approximation one-sided tests for two independent samples were then applied using SAS 9.3 (SAS Institute, Inc. 2011) to test for significant differences between mean pairwise relatedness coefficients, $r_{\mathrm{xy}}$, upstream and downstream of putative barrier sites. Higher mean relatedness values would be in the half-sib (0.25) to full-sib (0.45) range, where half-sibs share one parent and full-sibs share two parents (Kuligowski et al. 2005).

Table 2 Brook Trout microsatellites screened for population genetic analysis (King et al. 2003, 2005)

\begin{tabular}{llll}
\hline Locus & Dye & Allele size range (bp) & GenBank accession number \\
\hline Master Mix 1: & & & AY168192 \\
Sfo-C88 & FAM (blue) & $170-205$ & AY168193 \\
Sfo-C113 & FAM (blue) & $125-170$ & AY168197 \\
Sfo-D75 & NED (black) & $165-250$ & AY168199 \\
Sfo-D100 & HEX (green) & $200-275$ & AY168187 \\
Master Mix 2: & & & AY168194 \\
Sfo-C24 & FAM (blue) & $110-190$ & AY168195 \\
Sfo-C115 & FAM (blue) & $225-370$ & AF525207 \\
Sfo-C129 & HEX (green) & $215-270$ & $270-450$ \\
Ssa-D237 & HEX (green) & & \\
\hline
\end{tabular}


To test the prediction that there would be significantly greater individual assignment probabilities upstream of the barrier when compared to downstream of the barrier, we applied STRUCTURE 2.3.1 (Pritchard et al. 2000) to estimate the probability $(Q)$ that an individual belonged to one of $\mathrm{K}=2$ populations sampled upstream of the barrier or downstream of the barrier. For each putative barrier (10 sites total), five replicate simulations were run, using the admixture model, with a 100,000 burn-in period and 1,000,000 Markov Chain Monte Carlo (MCMC) iterations. Wilcoxon, nonparametric normal approximation one-sided tests for two independent samples were then applied using SAS 9.3 (SAS Institute, Inc. 2011) to test for significant differences between mean $Q$ upstream and the mean $Q$ downstream values for each sample site.

\section{Results}

Gradient and barrier height

Gradient was eliminated as a significant variable because linear regression and correlation analysis identified height as the preferred predictive variable. Multiple linear regression tests of significance for relationships between channel gradient (degrees), barrier height (m), and genetic differentiation $\left(F_{S T}\right)$ using SAS 9.3 (SAS Institute, Inc. 2011) resulted in significant relationships between height and $F_{S T}\left(r^{2}=0.54, F=9.36, P=0.02\right)$, and no significant predictive relationship between gradient and $F_{S T}$. Pearson correlation analysis identified a significant correlation between height and gradient $(r=0.56, p=0.02)$ using SAS 9.3 (SAS Institute, Inc. 2011). Barrier height was chosen as the preferred predictive variable because Pearson correlation analysis identified a significant correlation between barrier height and $F_{S T}(r=0.73, p=0.02)$, and no significant correlation between gradient and $F_{S T}$.

Genetic diversity and barrier height

Mean upstream diversity values included $48 \pm 6$ total alleles, $6.07 \pm 0.71$ average number of alleles per locus $(A)$, and $0.59 \pm 0.05$ average gene diversity per locus $(H)$ (Table 3). There was no significant difference between the upstream- and downstream-barrier samples for the total number of alleles (Wilcoxon, normal approximation, $Z=0.04, P<0.49$ ), average number of alleles per locus $(A)$ (Wilcoxon, normal approximation, $Z=0.00$, $P<0.50)$, and average gene diversity per locus $(H)$ (Wilcoxon, normal approximation, $Z=0.38, P<0.35$ ).

Total alleles $(F=8.98, P>0.02)$ and average number of alleles per locus $(A)(F=8.98, P>0.02)$ became significantly greater in relation to barrier height, but piecewise linear regression did not identify a break point in barrier height at which total alleles or $A$ upstream of the barrier started to decrease. $H$ values became significantly greater in relation to barrier height starting at $4 \mathrm{~m}$ according to piecewise linear regression. In this case the linear model that included all heights to predict the relationship between barrier height and $H$ was statistically significant $\left(F=16.5, P>0.00, r^{2}=0.67\right.$, $\mathrm{MSE}=0.11)$, but the piecewise model that only included barrier heights $>4 \mathrm{~m}$ was a better fit $(F=28.8$, $P>0.00, r^{2}=0.83, \mathrm{MSE}=0.09$ ).

Differentiation and barrier height

Genetic differentiation $\left(F_{\mathrm{ST}}\right)$ values ranged from 0.00 at Cascades to 0.35 at Apple Orchard Falls (Table 3). $F_{\mathrm{ST}}$ values became significantly greater in relation to barrier height starting at $4 \mathrm{~m}$ according to piecewise linear regression. In this case the linear model that included all heights to predict the relationship between barrier height and $F_{\mathrm{ST}}$ was statistically significant $\left(F=9.36, P>0.02, r^{2}=0.54\right.$, MSE $=0.08)$, but the piecewise model that only included barrier heights $>4 \mathrm{~m}$ was a better fit $(F=16.3, P>0.01$, $\left.r^{2}=0.76, \mathrm{MSE}=0.07\right)($ Fig. 2)

Relatedness and barrier height

The mean relatedness values, $r_{\mathrm{xy}}$, ranged from 0.18 to 0.59 for all individuals and up to 0.81 for individuals upstream of the Apple Orchard Falls site. Samples from the Saint Mary's Falls, Cabin Creek, Cascades, and Sassafras Falls populations exhibited mean relatedness values within the half-sib range ( 0.25 to 0.49$)$ and the Apple Orchard Falls site exhibited mean relatedness values within the full-sib range $(\geq 0.50)$ (Table 4$)$. There was no significant difference detected between mean relatedness values (Wilcoxon, normal approximation, $Z=-0.34, P<0.37$ ) upstream and downstream of all sites.

Mean relatedness values, $r_{x y}$, became significantly greater in relation to barrier height starting at $4 \mathrm{~m}$ according to piecewise linear regression. In this case the linear model that included all heights to predict the relationship between barrier height and mean relatedness was statistically 
Table 3 Population genetic metrics (mean \pm SE) for Brook Trout upstream (US) and downstream (DS) of putative barriers, including: total number of alleles, average number of alleles per locus $(A)$, average gene diversity $(H)$, probability of individual assignment $(Q)$, and population differentiation $\left(F_{\mathrm{ST}}\right)$. The $P$ values are the levels of significance for Wilcoxon one-sided tests for differences between the upstream and downstream values

\begin{tabular}{llllllllll}
\hline Site & \# alleles US & \# alleles DS & $A$ US & $A$ DS & $H$ US & $H$ DS & $Q$ US & $Q$ DS & $F_{S T}$ \\
\hline APOR & 13 & 32 & 1.63 & 4.00 & 0.16 & 0.39 & 0.98 & 0.94 & 0.35 \\
SASS & 26 & 24 & 3.25 & 3.00 & 0.45 & 0.40 & 0.87 & 0.88 & 0.04 \\
MORG & 57 & 52 & 7.13 & 6.63 & 0.66 & 0.65 & 0.67 & 0.69 & 0.01 \\
CASC & 47 & 42 & 5.88 & 5.25 & 0.63 & 0.61 & 0.52 & 0.52 & 0.00 \\
CBCR & 36 & 34 & 4.50 & 4.25 & 0.53 & 0.52 & 0.95 & 0.97 & 0.03 \\
PRBR & 59 & 56 & 7.63 & 7.50 & 0.71 & 0.68 & 0.53 & 0.53 & 0.01 \\
COLE & 71 & 71 & 8.88 & 9.13 & 0.72 & 0.69 & 0.57 & 0.57 & 0.02 \\
STMY & 34 & 50 & 4.25 & 6.38 & 0.47 & 0.69 & 0.94 & 0.87 & 0.15 \\
SHCS & 54 & 55 & 7.00 & 7.00 & 0.74 & 0.71 & 0.92 & 0.93 & 0.01 \\
SPBK & 69 & 65 & 8.63 & 8.13 & 0.72 & 0.70 & 0.78 & 0.74 & 0.01 \\
NFKS & 64 & 63 & 8.00 & 7.88 & 0.72 & 0.71 & 0.51 & 0.51 & 0.00 \\
Mean \pm SE & $48 \pm 6$ & $49 \pm 4$ & $6.07 \pm 0.71$ & $6.29 \pm 0.58$ & $0.59 \pm 0.05$ & $0.61 \pm 0.04$ & $0.75 \pm 0.06$ & $0.74 \pm 0.06$ & $0.06 \pm 0.03$ \\
$P$ values: & $<0.49$ & & $<0.50$ & & $<0.35$ & & $<0.44$ &
\end{tabular}

significant $\left(F=24.5, P>0.00, r^{2}=0.75, \mathrm{MSE}=0.06\right)$, but $>4 \mathrm{~m}$ was a better fit $\left(F=39.4, P>0.00, r^{2}=0.89\right.$, the piecewise model that only included barrier heights MSE $=0.05)$ (Fig. 3).

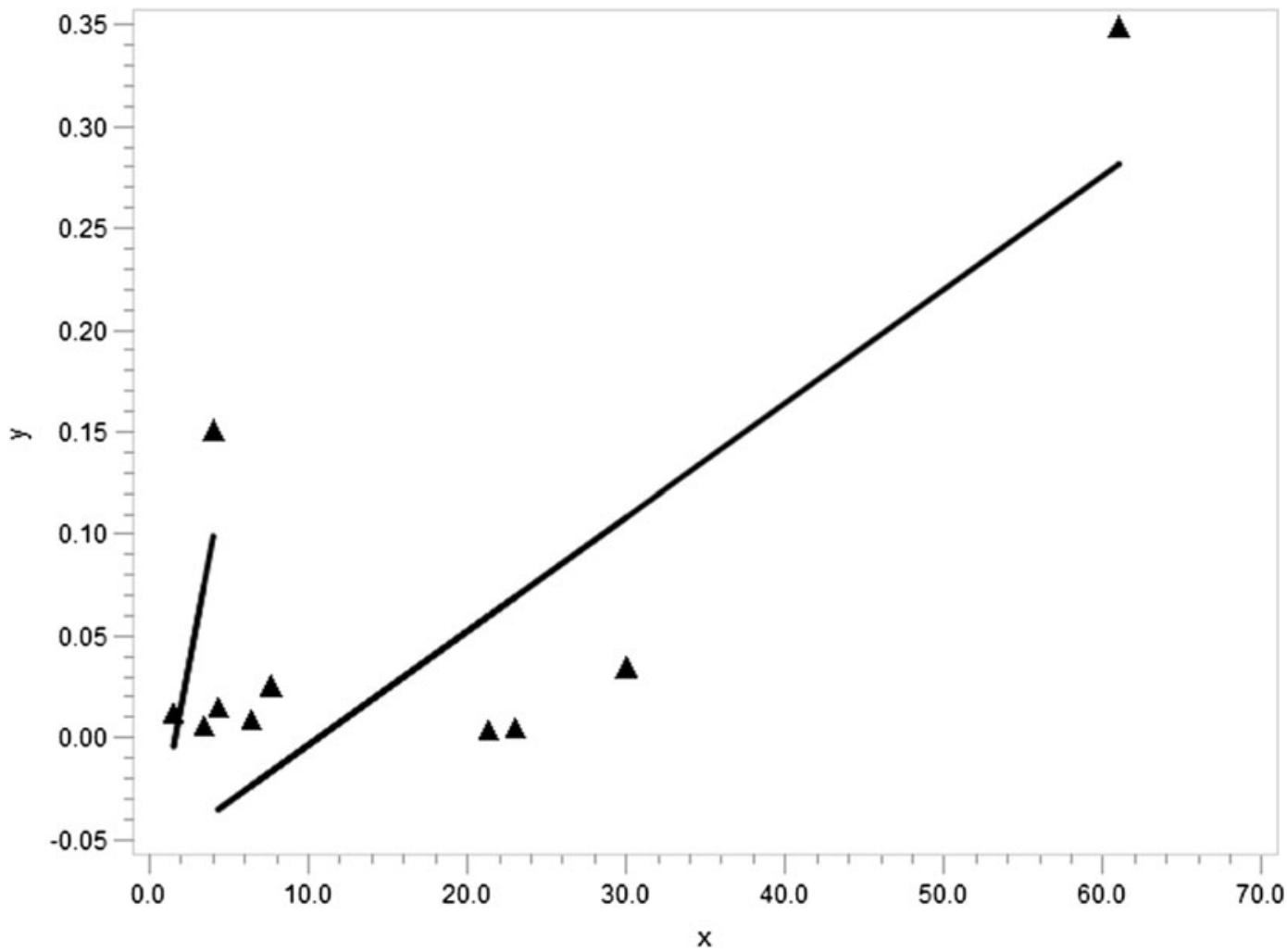

Fig. 2 Piecewise regression identified a breakpoint in height (x) where $F_{\mathrm{ST}}$ values (y) became more significantly related to height at $>4 \mathrm{~m}$ 
Table 4 Relatedness values for all Brook Trout sample sites. Mean relatedness, $r_{\mathrm{xy}}$, values (Queller and Goodnight 1989) were calculated for upstream (US) (30 individuals), downstream (DS) (30 individuals), and all combined upstream and downstream (60 individuals) barrier samples per site

\begin{tabular}{lllll}
\hline Site & Height $(\mathrm{m})$ & $r_{\mathrm{xy}}(\mathrm{all})$ & $r_{\mathrm{xy}}(\mathrm{US})$ & $r_{\mathrm{xy}}(\mathrm{DS})$ \\
\hline APOR & 61.0 & 0.59 & 0.81 & 0.42 \\
SASS & 30.0 & 0.33 & 0.34 & 0.33 \\
MORG & 23.0 & 0.23 & 0.21 & 0.22 \\
CASC & 21.3 & 0.28 & 0.22 & 0.22 \\
CBCR & 7.6 & 0.28 & 0.27 & 0.28 \\
PRBR & 6.4 & 0.19 & 0.17 & 0.18 \\
COLE & 4.3 & 0.18 & 0.17 & 0.18 \\
STMY & 4.0 & 0.34 & 0.37 & 0.26 \\
SHCS & 3.4 & 0.19 & 0.18 & 0.19 \\
SPBK & 1.5 & 0.19 & 0.16 & 0.20 \\
Mean \pm SE & & $0.28 \pm 0.04$ & $0.29 \pm 0.06$ & $0.25 \pm 0.02$ \\
\hline
\end{tabular}

Individual assignment probabilities and barrier height

the upstream-barrier sample at a site and 0.52 to $0.97(Q)$ that individuals were correctly assigned to the downstream-barrier sample for each site (Table 3). There was no significant difference between the upstream- and downstream-barrier samples for $Q$ probability of individual assignment (Wilcoxon, normal approximation, $Z=0.15$,

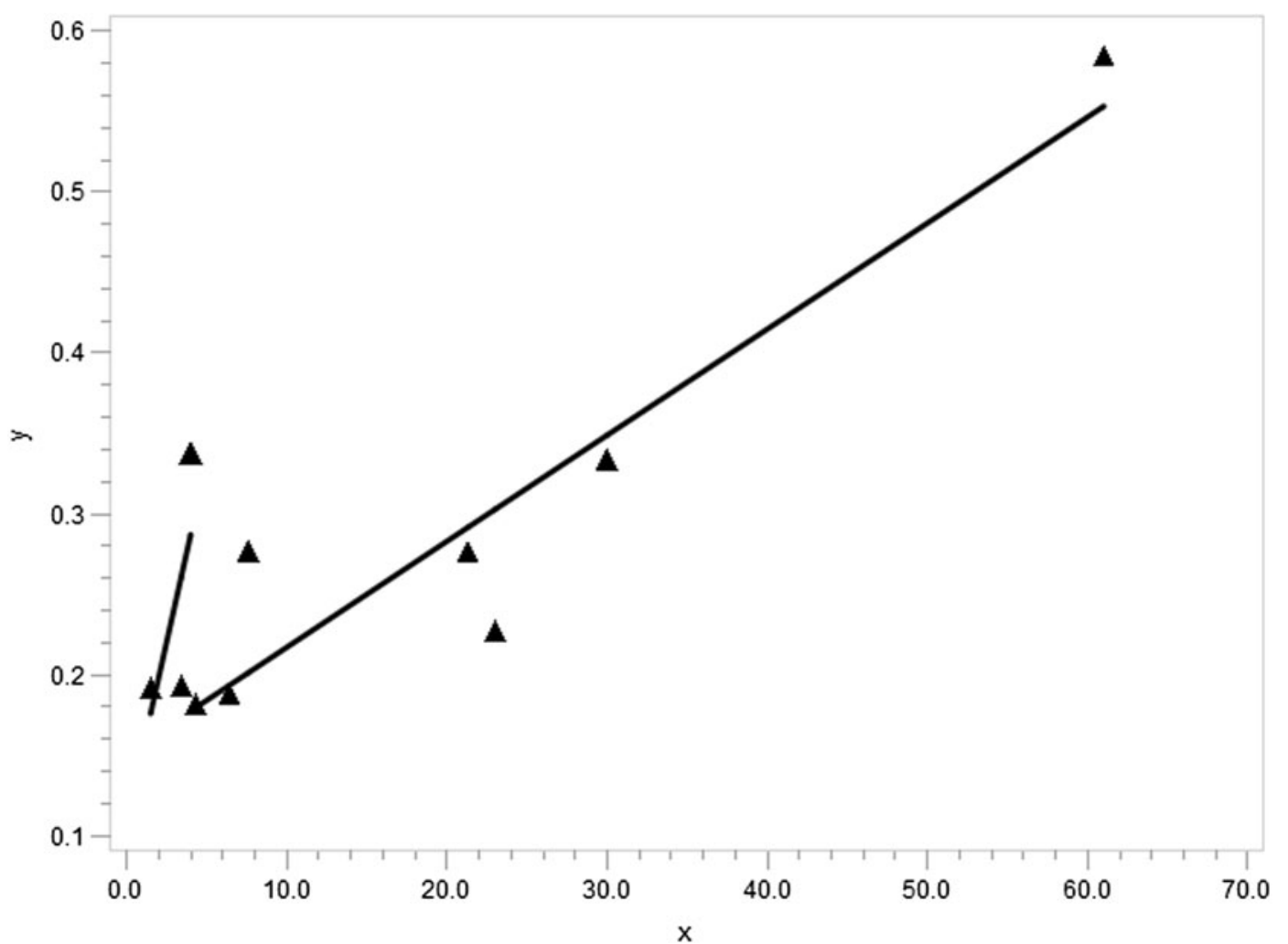

Fig. 3 Piecewise regression identified a breakpoint in height $(\mathrm{x})$ where mean relatedness, $r_{x y}$ values (y) became more significantly related to height at $>4 \mathrm{~m}$ 
$P<0.44)$. In addition, linear regression did not identify a significant relationship between mean $Q$ upstream and barrier height $(F=1.68, P>0.23)$.

The non-barrier site, North Fork Stony Creek, resulted in a $0.51 Q$ that individuals were correctly assigned to the upstream-barrier sample and $0.51 Q$ that individuals were correctly assigned to a downstream-barrier sample. Putative barrier sites that had similar $Q$ values to the North Fork Stony Creek non-barrier site $(Q=0.51)$ included the Portage Brook site $(Q=0.53)$, with a barrier height of $6.4 \mathrm{~m}$, and the Cascades site $(Q=0.52)$, with a barrier height of $21.3 \mathrm{~m}$. These sites with lower $Q$ values also had low $F_{\mathrm{ST}}$ values of 0.00 (North Fork Stony Creek, $0 \mathrm{~m}$ ), 0.01 (Portage Brook, $6.4 \mathrm{~m}$ ), and 0.00 (Cascades, 21.3). Sites that had higher $Q$ probabilities of assignment such as Apple Orchard Falls $(Q$ upstream $=0.98, Q$ downstream $=0.94)$ and Sassafras Falls $(Q$ upstream $=0.87, Q$ downstream $=0.88)$ also had higher $F_{\mathrm{ST}}$ values of 0.35 and 0.04 respectfully (Table 3 ).

\section{Discussion}

This was the first study conducted to investigate the population genetic effects of putative natural barriers across a wide range of heights on Brook Trout populations across two ecoregions of the eastern United States. The overall goal was to evaluate effects of landscape features, barriers, on Brook Trout population genetics and to identify a barrier height threshold of population genetic effects. Genetic diversity, differentiation, individual assignment, and relatedness analyses were applied to microsatellite multilocus genotype data to look for empirical indicators of dispersal.

This study predicted that heights barring upstream movement would result in lower mean total alleles, mean gene diversity per locus $(H)$, and number of alleles per locus $(A)$ upstream of the barrier. However, statistically lower mean total alleles, $H$, and $A$ were not observed in this study, in contrast to results of previous studies documenting significant differences in $A$ and $H$ between upstream- and downstream-barrier samples. This study also predicted that heights that were a barrier to upstream movement would result in higher $F_{\mathrm{ST}}$ values, which was the case in this study and previous studies (Castric et al. 2001; Taylor et al. 2003; Yamamoto et al. 2004; Poissant et al. 2005; Wofford et al. 2005; Whiteley et al. 2006; Deiner et al. 2007; Small et al. 2007; Guy et al. 2008).

Although this study did not identify a significant difference between upstream and downstream values for individual assignment probability, $Q$, or a significant relationship between $Q$ and barrier height, we did observe differences in $Q$ values when comparing sites. This study provides evidence that individual assignment test-based analyses is effective in detecting short-lived multilocus structures, presumably identifying distinct patterns in family-level variation due to a limited number of alleles observed in a given stream reach. Neville et al. (2006) identified separate upstream and downstream-barrier clustering of Lahontan cutthroat trout Oncorhynchus clarkii henshawi individuals using the STRUCTURE algorithm (Pritchard et al. 2000). Therefore, individual assignment probability may prove to be more useful for identifying population structuring at larger spatial scales.

This study also predicted that mean relatedness values upstream of the barrier would significantly increase in relation to height, which was the case. In this study a total of five of 10 sites had mean $r_{\mathrm{xy}}$ values at least at the half-sib level $(0.25$ to 0.49$)$, where the offspring in a family share one parent, or the full-sib level $(\geq 0.50)$, where the offspring in the family share two parents. The high relatedness value for the upstream-barrier sample at the APOR site (0.81) supports the hypothesis that the natural barrier $(61 \mathrm{~m})$ at the Apple Orchard Falls site is a complete barrier to upstream dispersal for Brook Trout. This indicates that the Brook Trout populations upstream of the barrier at the Apple Orchard Falls are at risk for genetic isolation, loss of genetic diversity, and increased potential for accumulated inbreeding due to a limited number of families and lack of dispersal of new spawners from downstream. At the local scale, these effects of genetic isolation may affect persistence of a population through decreased fecundity and adaptive potential over time (Quattro and Vrijenhoek 1989; Morita and Yamamoto 2002; Herbinger et al. 2006).

Significant effects of barriers on differentiation and mean relatedness were observed starting at $4 \mathrm{~m}$ heights, where piecewise regression identified a threshold value at which average gene diversity per locus $(H), F_{S T}$, and mean relatedness would continue to increase. This potential barrier height threshold is greater than the height criterion identified for Brook Trout based on physical criteria and jumping ability $(0.74 \mathrm{~m})$. Applying barrier- 
height criteria, such as $0.74 \mathrm{~m}$ with a $0.40 \mathrm{~cm}$ minimum pool depth (Kondratieff and Myrick 2006) and $4 \mathrm{~m}$ heights to Brook Trout movement universally may not be appropriate for all putative barriers on the landscape. The ability of a fish to disperse upstream may be due to other factors besides height such as slope, velocity, and availability of resting pools adjacent to the barrier. Different flow conditions may offer temporary upstream dispersal opportunities as higher water allows the fish to be closer to the top of the barrier. Nonetheless, a height threshold of $4 \mathrm{~m}$, identified by more significant differentiation and relatedness values, could be used as a minimum height for investigating the presence of population genetic effects.

This potential $4 \mathrm{~m}$ barrier height threshold must be considered with the caveat that genotypic frequencies at particular sites sampled may depart from assumptions of migration-drift equilibrium underlying the $F_{\mathrm{ST}}$ metric (Weir and Cockerham 1984) and Hardy-Weinburg Equilibrium (HWE) related to genetic diversity metrics (Wright 1965). In addition, relatedness and differentiation analyses are affected by our ability to sample the entire population across all available habitats, as opposed to oversampling individuals from a small number of families from a small number of redd locations (Herbinger et al. 2006; Hudy et al. 2010). These analyses were based on samples of 30 individuals upstream and downstream of each putative barrier, which may not reflect all multilocus genotypes present in every individual in the larger population from which they were sampled. Percentages of the total habitat sampled upstream of the barrier, calculated as (stream length sampled/total stream length)*100, ranged from 0.23 to $10.8 \%$, and sampling a larger percentage of the available habitat may have resulted in more individuals from the population that have different multilocus genotypes. For example, we sampled $0.12 \mathrm{~km}$ of the $1.97 \mathrm{~km}$ total available upstream of the Apple Orchard Falls site and $0.10 \mathrm{~km}$ of the $29.5 \mathrm{~km}$ total available upstream of the Saint Mary's Falls site.

Prioritization and management implications

This study shows that natural barriers $>4 \mathrm{~m}$ affected upstream dispersal of Brook Trout, which resulted in effects on population genetic diversity, differentiation, and relatedness at the local scale. Effects of natural and anthropogenic barriers of similar heights should have similar potential effects on the local population genetic diversity and population genetic structure (Deiner et al. 2007). Therefore, inferences from this study are relevant to anthropogenic barriers as well. Inferring these effects to larger scales that include multiple local populations isolated upstream of barriers, managers can use the $4 \mathrm{~m}$ threshold to prioritize locations for Brook Trout conservation genetics and restoration or modification of anthropogenic barriers to upstream Brook Trout spawner dispersal.

Kinship analysis reveals that the fewer the number of families, the fewer the number of spawners, which may put the population at risk from accumulated inbreeding, increased effects due to genetic drift, and increased variance in spawning success (Ryman and Laikre 1991; Herbinger et al. 2006). Relatedness analysis for the Apple Orchard Falls site suggested a need to increase the availability of diverse spawning pairs of locally-derived Brook Trout and to increase census size to prevent inbreeding (Wang et al. 2002; Small et al. 2009). Stocking history should be factored into any supplementation plan in relation to previously stocked census sizes and years. The availability of habitat isolated upstream of the natural barrier may factor into the success of increases in census size and supplementation, especially at the Apple Orchard Falls site with only $1.97 \mathrm{~km}$ of available habitat upstream of the barrier.

Future research needed

Traditional population genetic diversity and differentiation measures assume that investigators have observed all representative alleles and genotypes in a population, which may require more extensive sampling throughout the entire watershed to make sure all dispersing trout individuals have been sampled. Further related long-term research studies that include random sampling of individuals in all age-classes throughout all available habitat within the stream network would ensure a more representative sample of all genotypes that are present (Whiteley et al. 2006). Brook Trout habitat is becoming increasingly fragmented throughout the species' native range (Hudy et al. 2008). Therefore, opportunities to sample high-density native Brook Trout populations on the landscape are rare. If sites exist that are accessible, more population genetic sampling from 
natural barrier sites between 4 to $20 \mathrm{~m}$ would be helpful to further quantify the effects of increasing barrier height on differentiation and relatedness.

For this study, of the 18 high-density Brook Trout populations identified adjacent to natural barriers, eight sample locations were eliminated due to the influence of stocking. Stocking can confound the population genetic effect of barrier height if stocking is carried out only upstream or downstream of a barrier or if distinct lineages have not had time to thoroughly mix among the sampled populations. To further characterize effects of stocking on native Brook Trout genetic diversity in sampled populations, it would be informative to include allozyme or mitochondrial DNA analysis of stocked strains to quantify introgression of stocked alleles into native alleles in populations.

Further long-term data analysis should combine long-term mark-recapture, allelic diversity, $F_{\mathrm{ST}}$ estimation, individual assignment analysis, and kinship analysis data with stocking history in stream channels with putative barriers to quantify dispersal in both the upstream and downstream directions. This study did not identify every spawning redd and assign every Brook Trout individual to its redd, which is how to verify that individuals are dispersing between more than one redd (Hudy et al. 2010). Collecting data from all age classes throughout all available habitats upstream and downstream of each barrier over $\geq 5$ generations would eliminate any potential bias that these kinship datasets represent (Hansen et al. 1997; Whiteley et al. 2006). In addition, incorporating pedigree analysis (Coombs et al. 2010) with mark-recapture data from permanent PIT tag readers could be applied to further document how specific parents and offspring are dispersing from originating redds in relation to barriers (Hudy et al. 2010).

Acknowledgments This study was funded by the USDA Forest Service (Northern Research Station, Southern Research Station, and Region 9) and the Virginia Tech Department of Fish and Wildlife Conservation. We thank K. Nislow for his feedback on this study and help with data analysis. We thank the U.S. Geological Survey, Conte Anadromous Fish Laboratory for providing laboratory facilities for processing fin clip samples. We thank B. Letcher, J. Coombs, P. Schueller, and G. Mendez for their help in the fish genetics laboratory. We thank J. Kuykendall and R. Stidham for logistical support. We also thank B. Flynn, C. B. Fox, A. Palmeri, J. Emmel, M. O'Melia; D. Belkoski, D. Hagedorn, J. Herrala, P. Lung, A. May, and M. Vincie for their hard work in the field. All procedures performed as a part of this research were performed in accordance with ethical standards approved by the Virginia Tech Animal Care and Use Committee.

\section{References}

Adams SB, Frissell CA, Rieman BE (2000) Movements of nonnative brook trout in relation to stream channel slope. Trans Am Fish Soc 129:623-638

Bailey RG (2005) Identifying ecoregion boundaries. Environ Manag 34:S14-S26

Belford DA, Gould WR (1989) An evaluation of trout passage through six highway culverts in Montana. N Am J Fish Manag 9:437-445

Belkhir K, Castric V, Bonhomme F (2002) IDENTIX, a software to test for relatedness in a population using permutation methods. Mol Ecol Notes 2:611-614

Castric V, Bonney F, Bernatchez L (2001) Landscape structure and hierarchical genetic diversity in the brook trout (Salvelinus fontinalis). Evolution 55:1016-1028

Coombs JA, Letcher BH, Nislow KH (2010) PEDAGOG: software for simulating eco-evolutionary population dynamics. Mol Ecol Resour 10:558-563

D'Amelio S, Mucha J, Mackereth R, Wilson CC (2008) Tracking coaster brook trout to their sources: combining telemetry and genetic profiles to determine source populations. N Am J Fish Manag 28:1343-1349

Danzmann RG, Ihssen PE (1995) A phylogeographic survey of brook charr (Salvelinus fontinalis) in Algonquin park, Ontario based upon mitochondrial DNA variation. Mol Ecol 4:681-697

Danzmann RG, Morgan R, Jones M, Bernatchez L (1998) A major sextet of mitochondrial DNA phylogenetic assemblages extant in eastern north American brook charr (Salvelinus fontinalis): distribution and postglacial dispersal patterns. Can J Zool 76:1300-1318

Deiner K, Garza JC, Coey R, Girman DJ (2007) Population structure and genetic diversity of rainbow trout (Oncorhynchus mykiss) above and below natural and manmade barriers in the Russian river, California. Conserv Genet $8: 437-454$

Excoffier L, Laval G, Schneider S (2005) Arlequin, ver. 3.0: an integrated software package for population genetics data analysis. Evol Bioinformatics Online 1:47-50

Gibson JR, Haedrich RL, Wernerheim CM (2005) Loss of fish habitat as a consequence of inappropriately constructed stream crossings. Fisheries 30:10-17

Gosset C, Rives J, Labonne J (2006) Effect of habitat fragmentation on spawning migration of brown trout (Salmo trutta L.). Ecol Freshw Fish 15:247-254

Guy TJ, Gresswell RE, Banks MA (2008) Landscape-scale evaluation of genetic structure among barrier-isolated populations of coastal cutthroat trout (Oncorhynchus clarkii clarkii). Can J Fish Aquat Sci 50:1749-1762

Hall MR, Morgan II RP, Danzmann RG (2002) Mitochondrial DNA analysis of mid-Atlantic populations of brook trout: the zone of contact for major historical lineages. Trans Am Fish Soc 131:1140-1151

Hansen MM, Nielsen EE, Mensberg KLD (1997) The problem of sampling families rather than populations: relatedness among individuals in samples of juvenile brown trout (Salmo trutta L.). Mol Ecol 6:469-474

Hansen MM, Nielsen EE, Ruzzante DE, Bouza C, Mensberg KLD (2000) Genetic monitoring of supportive breeding in brown 
trout (Salmo trutta L.), using microsatellite DNA markers. Can J Fish Aquat Sci 57:2130-2139

Heggenes J, Beere M, Tamkee P, Taylor EB (2006) Genetic diversity in steelhead before and after conservation hatchery operation in a coastal, boreal river. Trans Am Fish Soc 135: 251-267

Henegariu O, Heerema NA, Dlouhy SR, Vance GH, Vogt PH (1997) Multiplex PCR: critical param and step-by-step protocol. BioTechniques 23:504-511

Herbinger CM, O'Reilly PT, Verspoor E (2006) Unravelling firstgeneration pedigrees in wild endangered salmon populations using molecular genetic markers. Mol Ecol 15:2261-2275

Hudy M, Thieling T, Gillespie N, Smith EP (2008) Distribution, status, and land use characteristics of subwatersheds within the native range of brook trout in the eastern United States. N Am J Fish Manag 28:1069-1985

Hudy M, Coombs JA, Nislow KH, Letcher BH (2010) Dispersal and within-stream spatial population structure of brook trout revealed by pedigree reconstruction analysis. Trans Am Fish Soc 139:1276-1287

Jones OR, Wang J (2009) Colony: a program for parentage and sibship inference from multilocus genotype data. Mol Ecol Resour Computer Program Note: 1-5

Kalinowski ST, Wagner AP, Taper ML (2006) ML-RELATE: a computer program for maximum likelihood estimation of relatedness and relationship. Mol Ecol Notes 6:576-579

Kanno Y, Vokoun J, Letcher B (2011) Sibship reconstruction for inferring mating systems, dispersal and effective population size in headwater book trout (Salvelinus fontinalis) populations. Conserv Genet 12:619-628

King TL, Julian SE, Coleman RL, Burnham-Curtis MK (2003) Isolation and characterization of novel tri-and tetra-nucleotide microsatellite DNA markers for brook trout, Salvelinus fontinalis. GenBank submission numbers: AY168187, AY168192, AY 168193, AY168194, AY168195, AY168197, AY168199. Available at: http://www.ncbi.nlm. nih.gov/nucleotide/

King TL, Eackles MS, Letcher BH (2005) Microsatellite DNA markers for the study of Atlantic salmon (Salmo salar) kinship, population structure, and mixed-fishery analyses. Mol Ecol Notes 5:130-132

Kondratieff MC, Myrick CA (2006) How high can brook trout jump? A laboratory evaluation of brook trout jumping performance. Trans Am Fish Soc 135:361-370

Kuligowski DR, Ford MJ, Berejikian BA (2005) Breeding structure of steelhead inferred from patterns of genetic relatedness among nests. Trans Am Fish Soc 134:1202-1212

McCracken GF, Parker CR, Guffey SZ (1993) Genetic differentiation and hybridization between stocked hatchery and native brook trout in Great Smoky Mountains National Park. Trans Am Fish Soc 122:533-542

Morita K, Yamamoto S (2002) Effects of habitat fragmentation by damming on the persistence of stream-dwelling charr populations. Conserv Biol 16:1318-1323

Neraas LP, Spruell P (2001) Fragmentation of riverine systems: the genetic effects of dams on bull trout (Salvelinus confluentus) in the Clark fork river system. Mol Ecol 10:1153-1164

Neville HM, Dunham JB, Peacock MM (2006) Landscape attributes and life history variability shape genetic structure of trout populations in a stream network. Landsc Ecol 21:901916
Perkins DL, Krueger CC, May B (1993) Heritage brook trout in northeastern USA: genetic variability within and among populations. Trans Am Fish Soc 122:515-532

Poissant J, Knight TW, Ferguson MM (2005) Nonequilibrium conditions following landscape rearrangement: the relative contribution of past and current hydrological landscapes on the genetic structure of a stream-dwelling fish. Mol Ecol 14: $1321-1331$

Poplar-Jeffers IO, Petty JT, Anderson JT, Kite SJ, Strager MP, Fortney RH (2009) Culvert replacement and stream habitat restoration: implications for brook trout management in an Appalachian watershed, U.S.A. Restor Ecol 17:404-413

Pritchard JK, Stephens P, Donnelly P (2000) Inference of population structure using multilocus genotype data. Genetics 155 : 945-959

Quattro JM, Vrijenhoek RC (1989) Fitness differences among remnant populations of endangered Sonoran topminnow. Science 245:976-978

Queller DC, Goodnight KF (1989) Estimating relatedness using genetic markers. Evolution 43:258-275

Reiser DW, Huang C, Beck S, Gagner M, Jeanes E (2006) Defining flow windows for upstream passage of adult anadromous salmonids at cascades and falls. Trans Am Fish Soc 135:668-679

Rogers SM, Curry RA (2004) Genetic population structure of brook trout inhabiting a large river watershed. Trans Am Fish Soc 133:1138-1149

Rousset F (2007) GENEPOP'007: a complete re-implementation of the GENEPOP software for windows and Linux. Mol Ecol Resour 8:103-106

Ryan S, Porth E, Laurie S (2007) A tutorial on the piecewise regression approach applied to bedload transport data. Gen. Tech. Rep. RMRS-GTR-189. U.S. Department of Agriculture, Forest Service, Rocky Mountain Research Station, Fort Collins, Colorado

Ryman N, Laikre L (1991) Effects of supportive breeding on the genetically effective population size. Conserv Biol 5:325329

SAS Institute, Inc. (2011) SAS/STAT ${ }^{\circledR} 9.3$ User's Guide. SAS Institute, Inc, Cary, North Carolina

Sheer MB, Steel EA (2006) Lost watersheds: barriers, aquatic habitat connectivity, and salmon persistence in the Willamette and lower Columbia river basins. Trans Am Fish Soc 135:1654-1669

Shrimpton JM, Heath DD (2003) Census versus effective population size in chinook salmon: large-and small-scale environmental perturbation effects. Mol Ecol 12:2571-2583

Small MP, McLellan JG, Loxterman J, Von Bargen J, Frye A, Bowman C (2007) Fine-scale population structure of rainbow trout in the Spokane river drainage in relation to hatchery stocking and barriers. Trans Am Fish Soc 136:301-317

Small MP, Currens K, Johnson TH, Frye AE, Von Bargen JF (2009) Impacts of supplementation: genetic diversity in supplemented and unsupplemented populations of summer chum salmon (Oncorhynchus keta) in Puget sound (Washington, USA). Can J Fish Aquat Sci 66:1216-1229

Taylor PW, Roberts SD (1999) Clove oil: an alternative anaesthetic for aquaculture. N Am J Aquac 6:150-155

Taylor EB, Stamford MD, Baxter JS (2003) Population subdivision in westslope cutthroat trout (Oncorhynchus clarkii lewisi) at the northern periphery of its range: evolutionary 
inferences and conservation implications. Mol Ecol 12: 2609-2622

Wang S, Hard JJ, Utter F (2002) Salmonid inbreeding: a review. Rev Fish Biol Fish 11:301-319

Weir BS, Cockerham CC (1984) Estimating $F$-statistics for the analysis of population structure. Evolution 38:1358-1370

Whiteley AR, Spruell P, Rieman BE, Allendorf FW (2006) Finescale genetic structure of bull trout at the southern limit of their distribution. Trans Am Fish Soc 135:1238-1253

Wilson CC, Stott W, Miller L, D'Amelio S, Jennings M, Cooper A (2008) Conservation genetics of lake superior brook trout: issues, questions, and directions. N Am J Fish Manag 28: $1307-1320$
Wofford JEB, Gresswell RE, Banks MA (2005) Influence of barriers to movement on within-watershed genetic variation of coastal cutthroat trout. Ecol Appl 15:628-637

Wright S (1965) The interpretation of population structure by $F$ statistics with special regard to systems of mating. Evolution 19:395-420

Yamamoto S, Morita K, Koizumi I, Maekawa K (2004) Genetic differentiation of white-spotted char (Salvelinus leucomaenis) populations after habitat fragmentation: spatial-temporal changes in gene frequencies. Conserv Genet 5:529-538 